\title{
Evaluation of six commonly used formulae for sonographic estimation of fetal weight in a Sri Lankan population
}

\author{
D M A Kumara', Hemantha Perera² \\ Sri Lanka Journal of Obstetrics and Gynaecology 2009; 31: 20-33
}

\begin{abstract}
Objective: To compare six commonly used formulae (Shepard, Campbell, Hadlock I, II, III, and IV) for estimation of fetal weight in Sri Lankan population.

Methods: A descriptive cross-sectional study conducted at Ward 9, Sri Jayewardenepura General Hospital, Kotte, Sri Lanka from the October to December 2007. The study included 86 singleton pregnancies. The fetal biometry biparietal diameter (BPD), head circumference (HC), abdominal circumference (AC), femur length (FL) - ultrasonically measured on the previous day of planned delivery, actual birth weights (ABW) taken within 30 minutes of delivery. Estimated fetal weight (EFW) from each equation calculated using basic biometric values for estimation of fetal weight. Statistical analysis done using Karl Pierson correlation.
\end{abstract}

Results: The highest positive correlation between the ABW and the EFW was seen in the Hadlock IV ( $r=0.836$ ). According to the area under the curve for each ROC curve Hadlock IV equation has the highest (0.849).

For fetuses less than $2.5 \mathrm{~kg}$ Hadlock IV has the highest sensitivity (75\%). All the equations have the high specificity which ranges from $93.6 \%$ to $100 \%$.

In fetuses more than $3.5 \mathrm{~kg}$ the Shepard has the highest sensitivity (90\%). The specificity is highest $(97.4 \%)$ in Hadlock IV. Even though the Hadlock IV is the best formula identified in our study to predict babies less than $2.5 \mathrm{~kg}$ out of whole population, it is not the best for prediction of a baby larger than $3.5 \mathrm{~kg}$ (Hadlock IV sensitivity $40 \%$ ) compared to Hadlock I (sensitivity $80 \%$ and specificity $89.5 \%$ ) which is the best formula to predict a baby more than $3.5 \mathrm{~kg}$.

\footnotetext{
${ }^{1}$ Registrar,

${ }^{2}$ Consultant Obstetrician and Gynaecologist, Sri Jayewardenepura General Hospital.
}

Corresponding author: D M A Kumara E mail:ajithmobb@yahoo.com
Conclusion: All formulae have adequate accuracy for estimating fetal weight in the population tested, Hadlock IV has the best accuracy.

Key words: Fetal weight, obstertrics sonography.

\section{Introduction}

Ultrasound is a basic diagnostic tool in obstetrics and its benefits extend from use in diagnosis of very early pregnancy to estimation of fetal weight at the time of delivery. Monitoring of fetal growth is a standard component of antenatal care.

The correct determination of the fetal weight prior to delivery accurately is utmostly important and greatly influences the clinical management, the outcome of pregnancy, delivery and survival of the newborn especially in cases such as fetal macrosomia, fetal growth restriction, breech presentation or in a trial of vaginal birth after previous caesarean section. Fetal weight estimation has a significant bearing on management decisions in labor, thereby markedly improving perinatal outcome ${ }^{1}$.

There are various techniques for fetal weight estimation. The two main methods for predicting birth weight are clinical and sonographic estimations ${ }^{2}$. Although the clinical estimation, based on abdominal palpation and fundal height, is easy, inexpensive and more helpful in developing countries, it is subjective and has no standard technique ${ }^{2}$.

Several formulae have been developed for estimating fetal weight in the late second and the third trimester. These formulae involve a variety of sonographically obtained biometric measurements. The sonographic estimation which is based on measurement of various fetal dimensions particularly $\mathrm{BPD}, \mathrm{HC}, \mathrm{AC}$ and $\mathrm{FL}$ is superior to clinical estimation but still needs instruments and well trained physicians $^{3}$.

Low as well as excessive fetal weight is associated with increased risk of complications during pregnancy, labor and neonatal life $e^{4-8}$. Therefore detection of poor fetal growth as well as fetal macrosomia is of utmost importance in obstetrics. 
An accurate means of estimating fetal weight using ultrasonography was first described by Campbell and Wilkin in $1975^{10}$. The advantage of this technique is that it relies on linear and/or planar measurements of in utero fetal dimensions that are definable objectively and are reproducible ${ }^{11}$. Sonagraphic measurement of the fetal parts provides a direct way of assessing fetal size and unlike clinical methods; the presence of oligohydraminos, polyhydramnios $_{12}$ or maternal obesity ${ }^{13}$ has minimal effect on its accuracy.

Numerous formulae have been published for the purpose of estimating fetal weight from one or more of the following fetal body measurements, BPD, HC, $\mathrm{AC}$ and $\mathrm{FL}^{10,14}$. Most commonly, a combination is used. The most popular formulae are Shepard, Warsof' $\mathrm{s}^{15}$ with Shepard's modification ${ }^{16}$ and Hadlock's ${ }^{17,18}$. These formulae are included in most ultrasound equipment packages.

Eventhough sonographic machines offer various different formulae for estimation of fetal weight, up to date there is no study which recommends the best formula for Sri Lankan women. This study is conducted to determine the applicability of these various formulae, developed in the west, in estimating fetal weight in Sri Lankan population. According to the results the most suitable formula/formulae can be determined or if results are not significantly different any formula can be used without preference

\section{Objectives}

The objective of the study was to compare the accuracy of the Shepard, Campbell, Hadlock I, II, III, and IV formulae in predicting the fetal birth weight and to determine the sensitivity, specificity of Shepard, Campbell, Hadlock I, II, III, and IV equations in predicting the fetal birth weight $<2.5 \mathrm{~kg}$ and $>3.5 \mathrm{~kg}$ weight categories.

\section{Materials and methods}

A descriptive cross-sectional study conducted at Ward 9, Sri Jayewardenepura general hospital, Kotte, Sri Lanka. The duration of the study period was three months, from October 2007 to December 2007. The study comprised of 86 pregnant women who delivered during the period of study at ward 9 above 28 weeks of period of gestation (POG). POG was calculated from last regular menstrual period (LRMP) and confirmed by early dating scan. The unit antenatal clinic protocol includes a mandatory dating scan. The participants of the study were explained in detail regarding the nature of the study and its benefits and only those who agreed to participate in the study were included.

Singleton pregnancy at or more than 28 weeks and those who delivered within 48 hours of the USS examination by elective caesarian section or by induction of labor were included on the study. Fetuses with congenital anomalies, the biometric measurements of those, which were unable to ascertain due to reasons like deeply engaged head, very thick abdominal wall etc. and Mothers who had not given the consent for the USS after adequate counseling were excluded from the study.

The fetal biometric measurements were taken previous day by principle investigator, of planned delivery and collected in a data sheet. The ultrasonographic measurements of $\mathrm{BPD}, \mathrm{HC}, \mathrm{AC}$ and $\mathrm{FL}$ were obtained using real-time, $\mathrm{B}$ mode equipped with $3.5 \mathrm{MHz}$ abdominal probe of Agilent ultrasound system. The actual birth weights were also entered into the data sheet after the delivery of the fetus.

The participants were explained about the procedure and were asked to evacuate the urinary bladder before the scanning. A female attendant was also present during the examination. The principle investigater performed all the ultrasonographic measurements. The BPD, $\mathrm{HC}, \mathrm{AC}$ and $\mathrm{FL}$ were measured in centimeters $(\mathrm{cm})$ and the fetal weight in kilograms. BPD was measured as the largest diameter between the outer and inner tables of the fetal skull at right angle to the falx at a plane slightly above and parallel to the canthomeatal line that includes the falx, thalamus, septum pellucidum and an oval head shape $^{32}$.

The $\mathrm{HC}$ is the length of the outer perimeter of the cranium, made on the same transaxial image of the fetal head. It was measured by using an electronic ellipse available on the ultrasound scanner. AC measurement was obtained in the transverse plane perpendicular to the long axis of the fetal aorta or spine at the Porto-umbilical vein complex within the liver ${ }^{33}$. FL was measured as the linear distance between the greater trochanter of the femur to the distal metaphysis ${ }^{34}$.

Estimated fetal weight from each equation was calculated separately using basic biometric values for estimation of fetal weight. Table 1 describes the formulas used for fetal weight estimation. 
Table 1. Formulae used for fetal weight estimation

\begin{tabular}{|c|c|c|}
\hline Source & Year & Formula \\
\hline Shepard - & 1982 & $\log _{10} B W=[-1.7492+(0.166 \times B P D)+(0.046 \times A C)-$ \\
\hline $\mathrm{BPD}, \mathrm{AC}$ & & $(0.002646 \times \mathrm{XAC} \times \mathrm{BPD})] \times 1000$ \\
\hline Campbell - AC & 1975 & $\log _{10} B W=-4.564+(0.282 X A C)-0.00331(A C)^{2}$ \\
\hline Hadlock I - AC, FL & 1985 & $\begin{array}{l}\log _{10} B W=1.304+(0.05281 \times A C)+(0.1938 \times F L)- \\
(0.004 \text { XAC X FL })\end{array}$ \\
\hline Hadlock II - BPD, AC, FL & 1985 & $\begin{array}{l}\log _{10} B W=1.335-(0.0034 \times \text { AC X FL })+(0.0316 \times \\
B P D)+(0.0457 \times A C)+(0.1623 \times \text { FL })\end{array}$ \\
\hline $\begin{array}{l}\text { Hadlock III - HC, AC, FL } \\
\text { XHC) }\end{array}$ & 1985 & $\begin{array}{l}\log _{10} B W=1.326-(0.00326 \times A C \times F L)+(0.0107 \\
+(0.0438 \times A C)+(0.158 \times F L)\end{array}$ \\
\hline Hadlock IV - BPD, HC, AC, FL & 1985 & $\begin{array}{l}\log _{10} B W=0.3596+(0.00061 X B P D X A C)+ \\
(0.0424 X A C)+(0.174 X F L)+(0.0064 X H C)- \\
(0.00386 X A C X F L\end{array}$ \\
\hline
\end{tabular}

Actual birth weights of all the fetuses were taken separately. Birth weight measurements were taken using a properly calibrated digital weighing machine. The birth weights were measured by trained nursing officers. It is known that delays of more than 7 days between the USS examination and birth might elevate error rates falsely, because each fetus has a variable rate of continued growth after USS examination until birth ${ }^{35}$. Thus, the method optimized the accuracy of ultrasound EFW by avoiding the confounder of continued fetal growth after USS examination.

Permission was taken from the ethical committee of Sri Jayewardenepura General Hospital. Informed consent was obtained from each pregnant woman before subjecting her in the study after adequate counseling.

The collected data were coded and entered into a computer. The statistical package for social sciences (SPSS) - 16, software was used for the analysis of data. The relationship of actual birth weight with that of the ultrasonographic estimation of fetal birth weight using Shepard, Campbell, Hadlock I, II, III, and IV equations were separately determined. Statistical analysis was done using Karl Pierson correlation between actual birth weight and estimated birth weight by each formula, using ROC curve for each formula and assessing sensitivity, specificity for prediction of babies less than $2.5 \mathrm{~kg}$ and more than $3.5 \mathrm{~kg}$ for each formula separately.

\section{Results}

The study population consists of 86 pregnant women whose fetuses were evaluated ultrasonically to obtain fetal biometric measurements. Tables 2 and 3 describes the distribution of the study sample according to age categories and parity respectively.

Table 2. Distribution of the study sample according to age categories

\begin{tabular}{lcc}
\hline Age group & Number & $\%$ \\
\hline$<20$ & 4 & $04.65 \%$ \\
$20-29$ & 41 & $47.67 \%$ \\
$30-39$ & 37 & $43.02 \%$ \\
$>40$ & 4 & $04.65 \%$ \\
Total & 86 & $100.00 \%$ \\
\hline
\end{tabular}

Table 3. Distribution of the study sample according to parity

\begin{tabular}{ccc}
\hline Parity & Number & $\%$ \\
\hline 1 & 31 & 36.04 \\
2 & 22 & 25.58 \\
3 & 18 & 20.93 \\
4 & 10 & 11.62 \\
5 & 4 & 04.65 \\
6 & 1 & 01.16 \\
Total & 86 & $100.0 \%$ \\
\hline
\end{tabular}

Sri Lanka Journal of Obstetrics and Gynaecology 
In the study population most of the participants (36.04\%) were in their first pregnancy and $25.58 \%$ and $20.93 \%$ of them were in 2 nd and 3 rd pregnancy respectively. Only few participants $(5.81 \%)$ were grand multiparous.

The actual birth weight ranged from $1.90 \mathrm{~kg}$ to $4.090 \mathrm{~kg}$ with a mean of $3.10 \mathrm{~kg}$ and standard deviation of $0.442 \mathrm{~kg}$. Table 4 describes the distribution of actual birth weights according the major birth weight categories.
Table 4. Distribution of actual birth weights according the major birth weight categories

\begin{tabular}{lcc}
\hline Actual birth weight & Frequency & Percentage \\
\hline $\begin{array}{l}\text { Low birth weight } \\
(<2500 \mathrm{~g})\end{array}$ & 8 & 9.3 \\
$\begin{array}{l}\text { Normal weight } \\
(2500 \text { g-3500 g) }\end{array}$ & 68 & 79.1 \\
$\begin{array}{l}\text { High weight baby } \\
(>3500 \text { g) }\end{array}$ & 10 & 11.6 \\
Total & 86 & 100.0 \\
\hline
\end{tabular}

Figures 1 to 6 display the correlation of ABW with the EBW assessed by each equation.

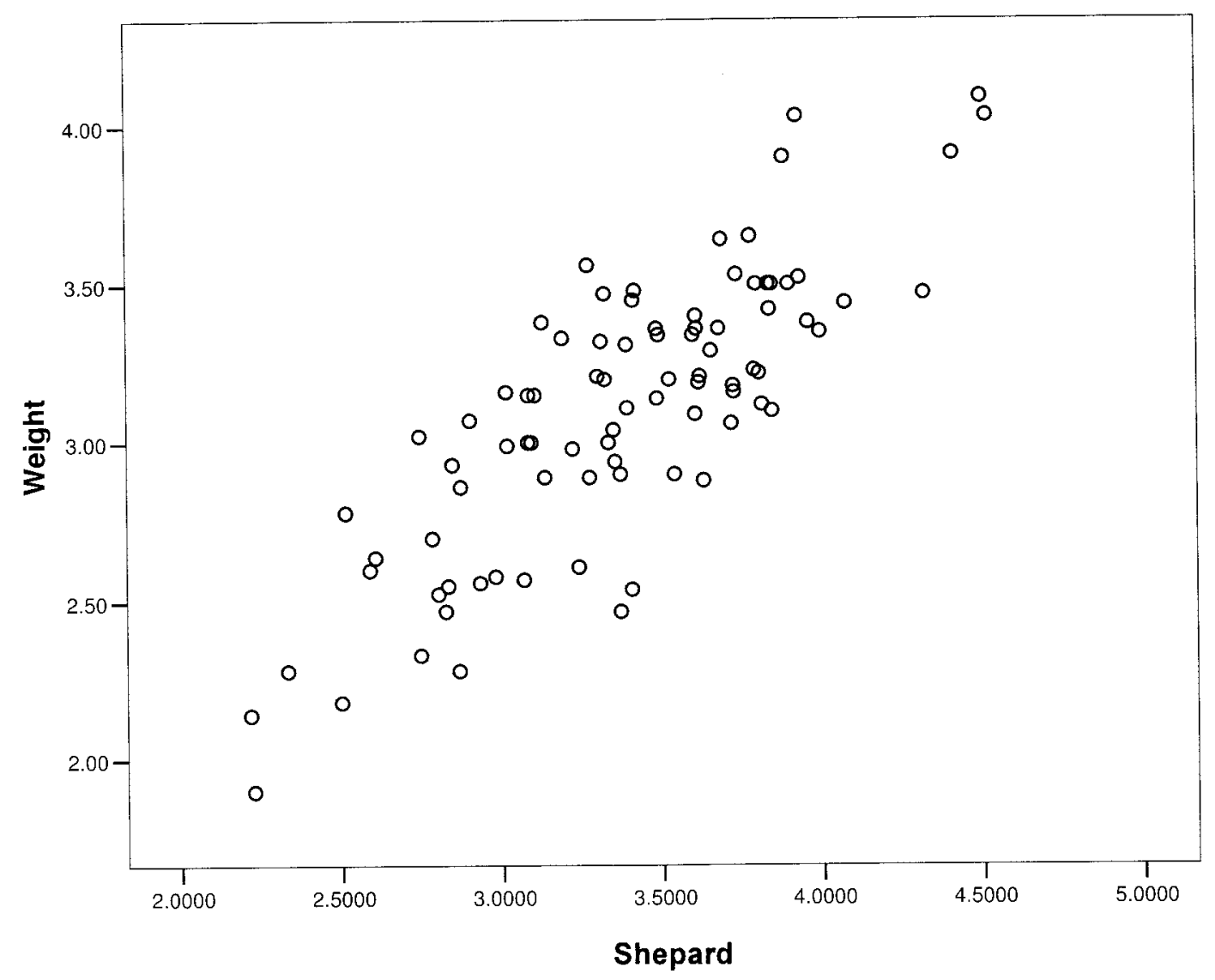

$\mathrm{r}=0.820958 \quad \mathrm{r} 2=0.674$

Figure 1. Correlation between the EBW by Shepard equation and the ABW for the whole population $(n=86)$ 
The scatter plot between actual birth weight and estimated birth weight by shepard equation shows positive correlation while $r$ value indicates that it is of high correlation $(r 2=0.674)$.

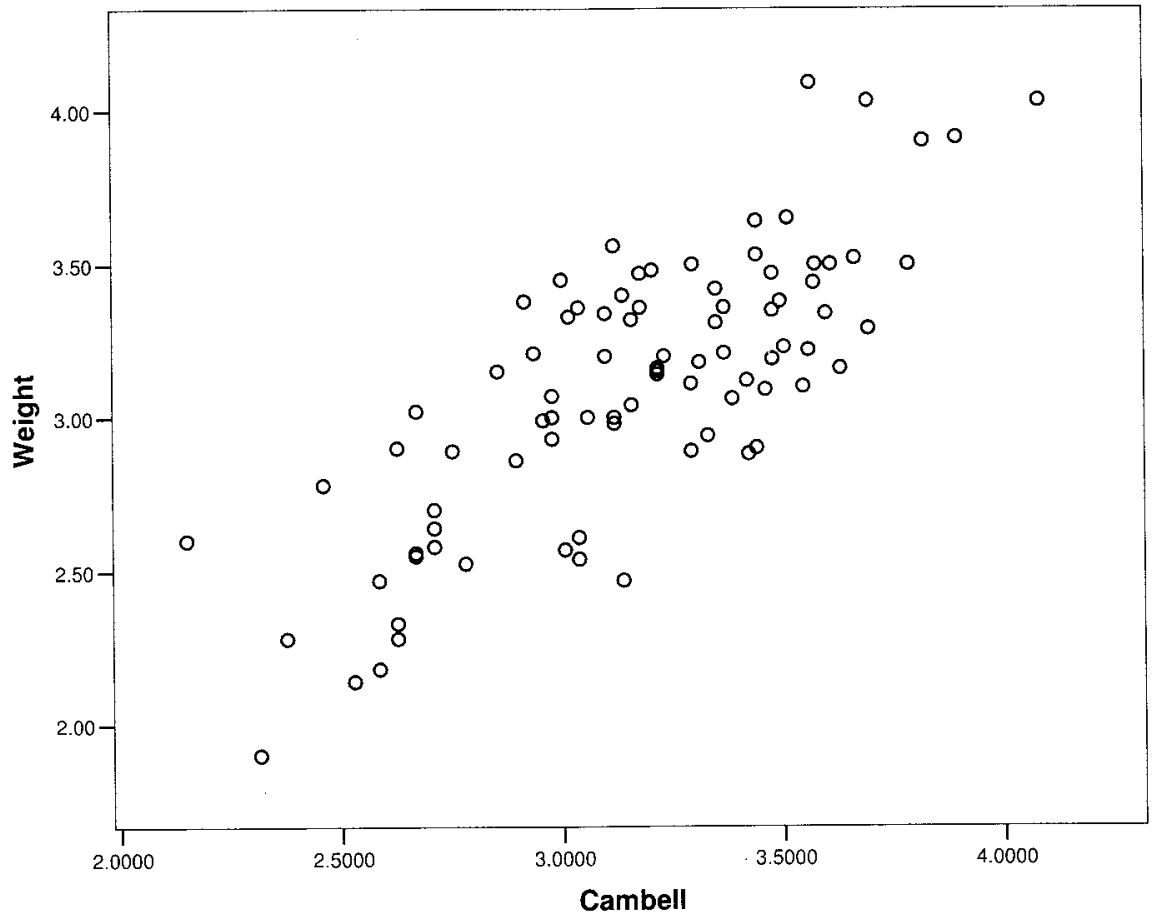

$\mathrm{r}=0.787142 \quad \mathrm{r} 2=0.620$

Figure 2. Correlation between the EBW by Campbell equation and the ABW for the whole population $(n=86)$.

The scatter plot between actual birth weight and estimated birth weight by Campbell equation shows positive correlation while $r$ value indicates that it is of a marked degree of correlation $(\mathrm{r} 2=0.620)$.

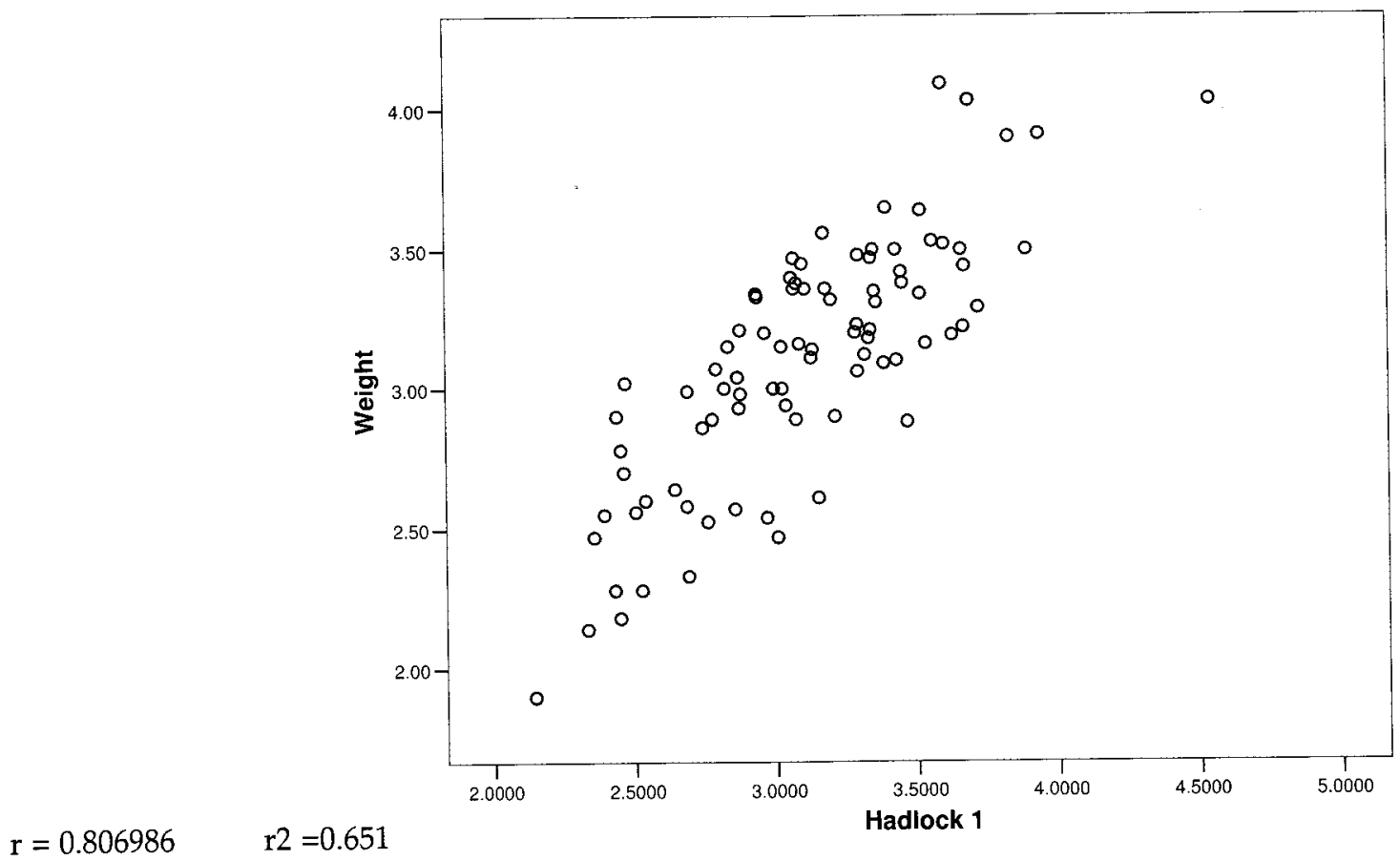

Figure 3. Correlation between the EBW by Hadlock I equation and the ABW for the whole population $(n=86)$. 
The scatter plot between actual birth weight and estimated birth weight by Hadlock I shows positive correlation while $r$ value indicates that it is of high correlation $(r 2=0.651)$.

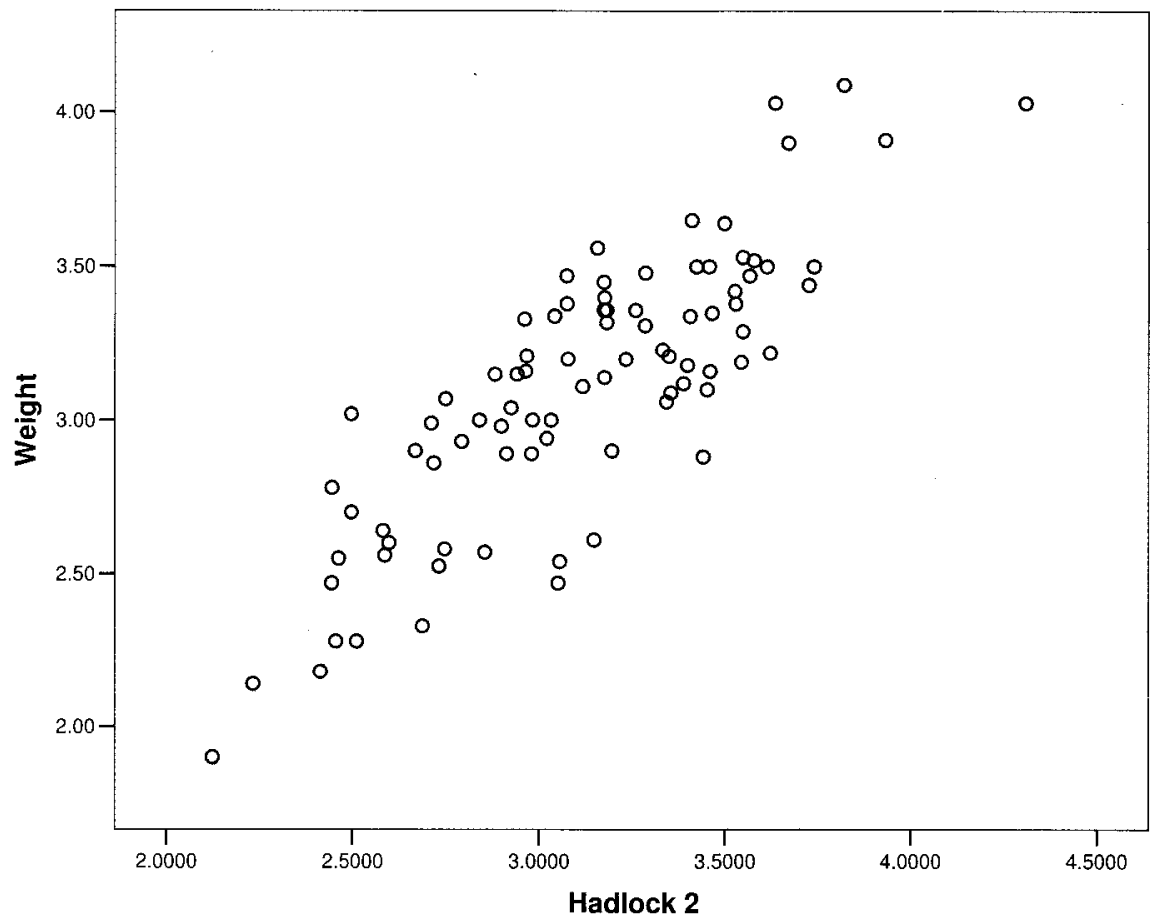

$\mathrm{r}=0.836421 \quad \mathrm{r} 20.700$

Figure 4. Correlation between the EBW by Hadlock II equation and the ABW for the whole population $(n=86)$.

The scatter plot between actual birth weight and estimated birth weight by Hadlock II shows positive correlation while $\mathrm{r}$ value indicates that it is of high correlation $(\mathrm{r} 2=0.700)$.

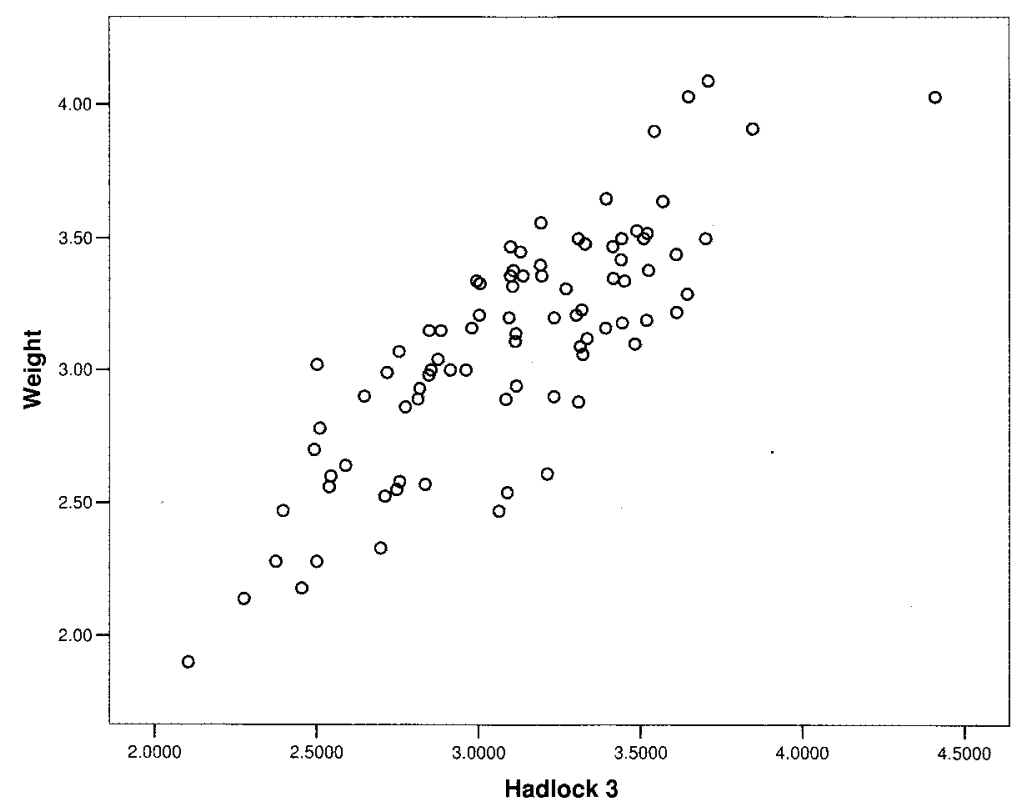

$\mathrm{r}=0.825522 \quad \mathrm{r} 2=0.681$

Figure 5. Correlation between the EBW by Hadlock III equation and the ABW for the whole population $(n=86)$. 
The scatter plot between actual birth weight and estimated birth weight by Hadlock III shows positive correlation while $\mathrm{r}$ value indicates that it is of high correlation $(\mathrm{r} 2=0.681)$.

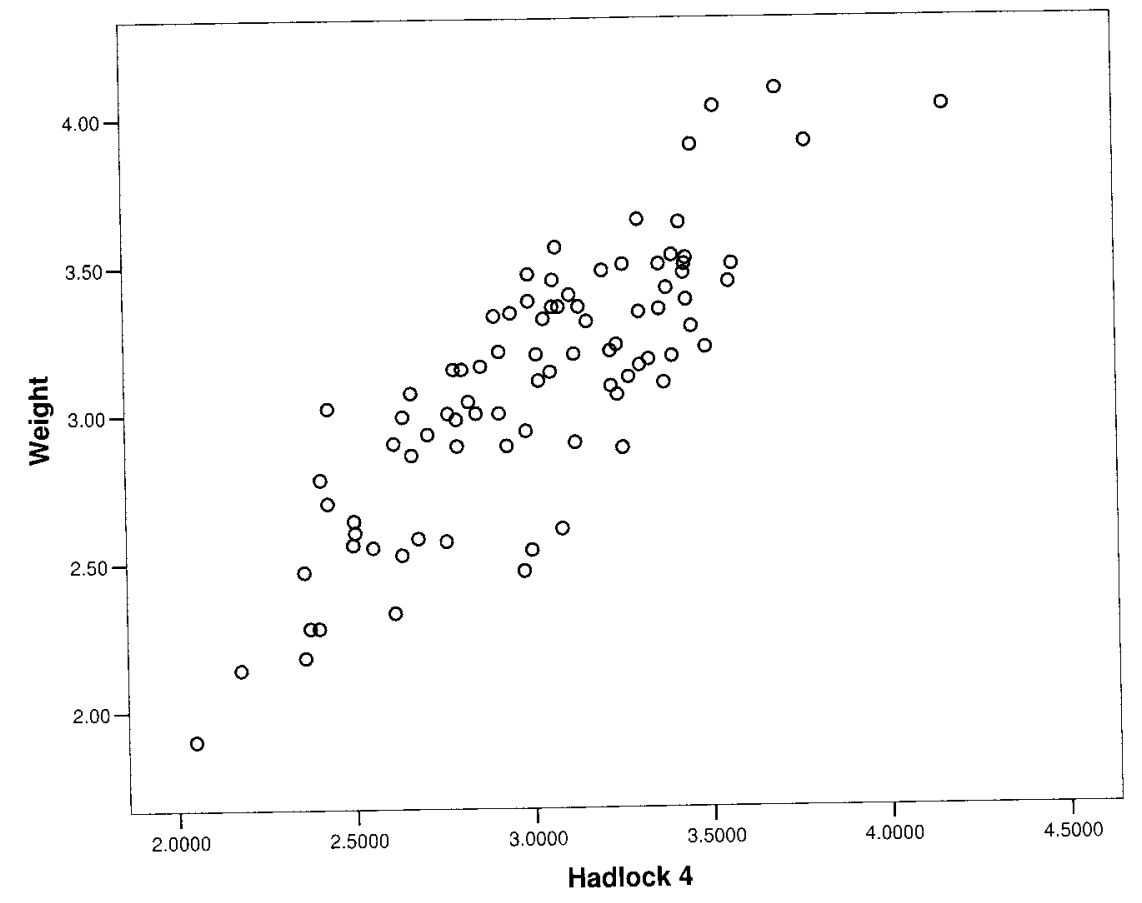

$r=0.83682 \quad r 2=0.700$

Figure 6. Correlation between the EBW by Hadlock IV equation and the ABW for the whole population $(n=86)$.

The scatter plot between actual birth weight and estimated birth weight by Hadlock IV shows positive correlation while $\mathrm{r}$ value indicates that it is of high correlation $(\mathrm{r} 2=0.700)$.

Correlation between actual birth weight and estimated birth weight for each equation which is described above is graphically represented in figure 7.

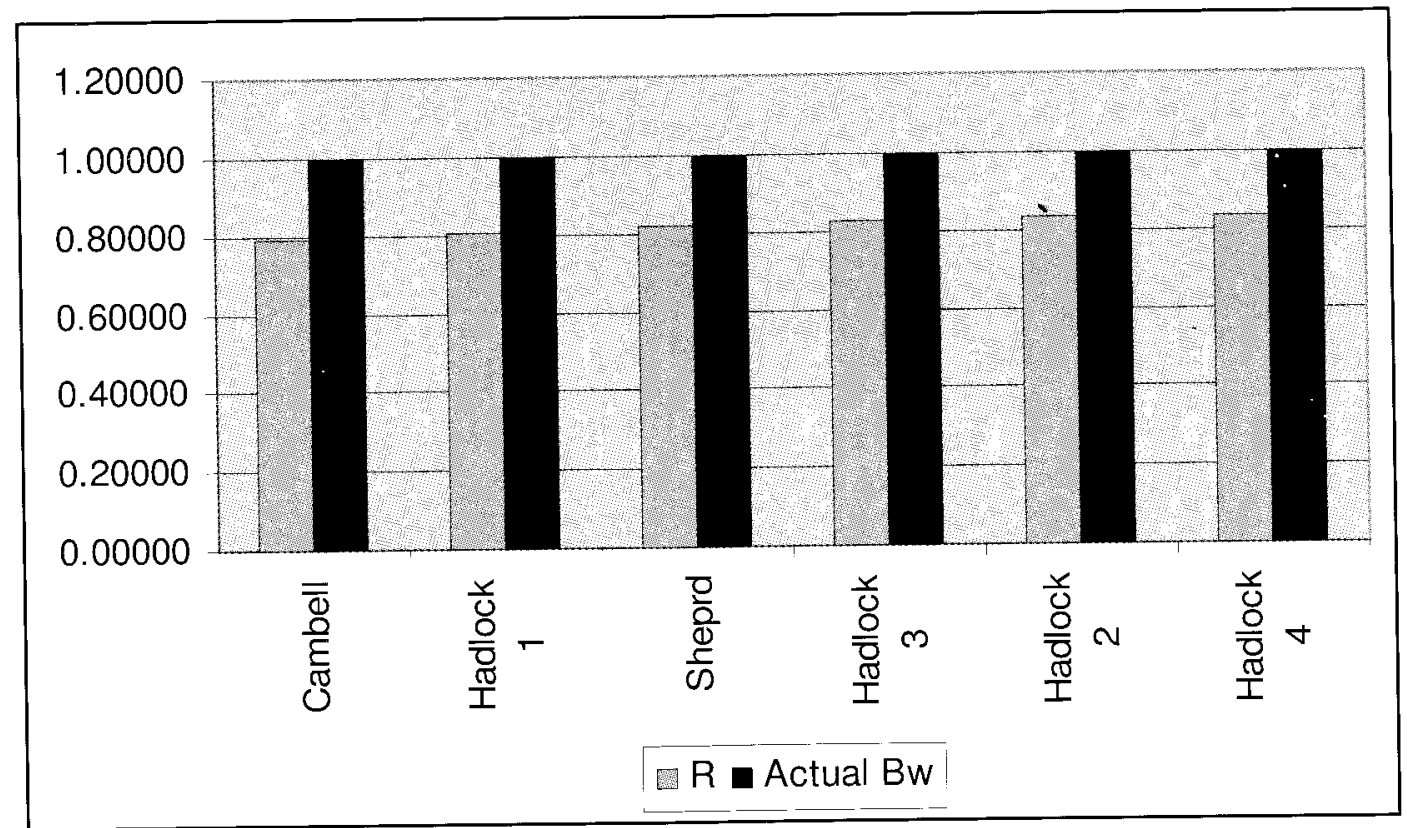

Figure 7. Correlations between $\mathrm{ABW}$ and EFW for each equation. 


\section{ROC Curve}

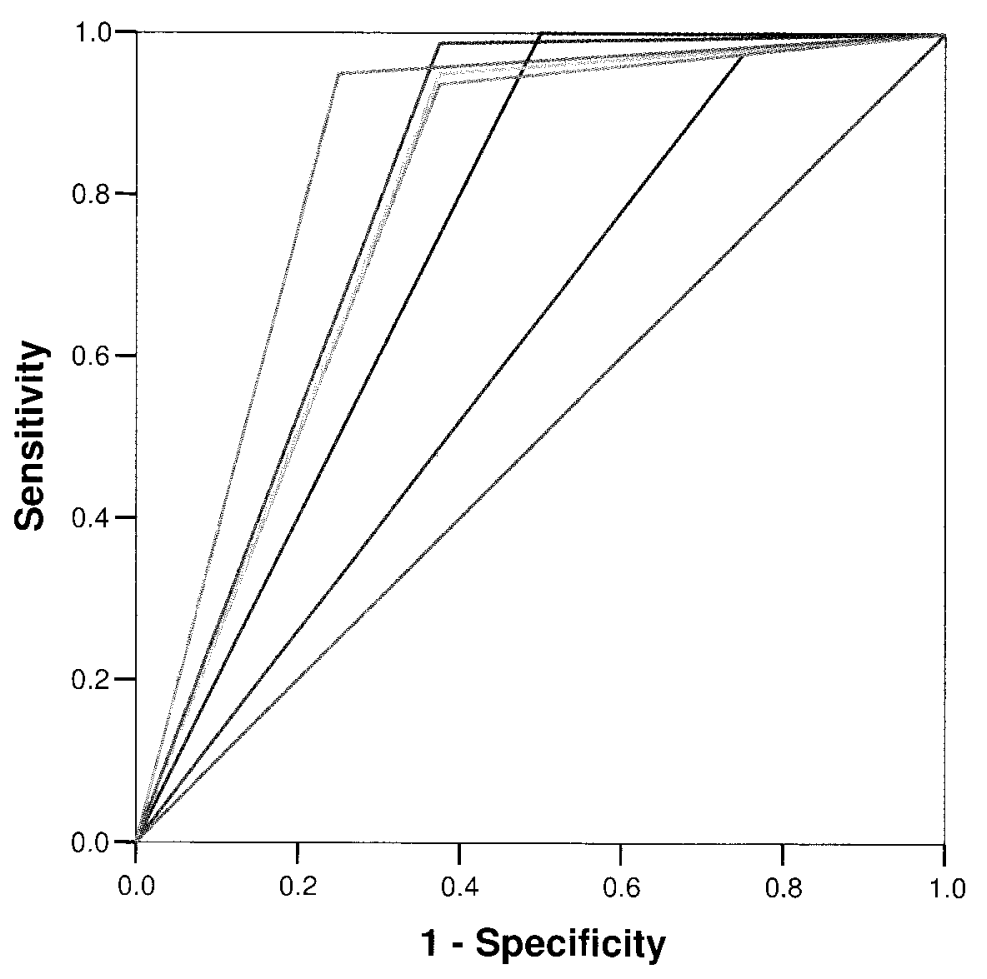

Source of the Curve

Shepard

Campbell

- ……... Hadlock 1

Hadlock 2

Hadlock 3

Hadlock 4

Reference Line

Diagonal segments are produced by ties.

Figure 8. ROC curves for each formula to determine the best formula.

According to the figure 08 Hadlock IV equation shows both high sensitivity and specificity while the Campbell method shows the lowest specificity and slightly higher sensitivity compared to other Hadlock IV.

Table 5. Area under the Curve for each formula

Test Result

Variable(s)

Shepard

Campbell

Hadlock1

Hadlock 2

Hadlock 3

Hadlock 4

Area

.750

.612

.780

.787

.806

、.849

In figure 8 the area under the curve for each ROC curve was given in Table 5. According to that Hadlock IV formula has the highest (0.849) area under the curve compared to Campbell formula which has the lowest (0.612) area under the curve. The Hadlock III equation has the second highest value (0.806) for area under the curve. 
Sensitivity and specificity for detection of a newborn $<2.5 \mathrm{~kg}$

Table 6. Sensitivity and specificity for detection of a newborn $<2.5 \mathrm{~kg}$ by Shepard equation

\begin{tabular}{lccc}
\hline & $<2.5 \mathrm{~kg}$ (actual) & $\mathbf{2 . 5} \mathbf{~ k g}$ (actual) & Total \\
\hline$<2.5 \mathrm{~kg}$ (Shepard) & 4 & 0 & 4 \\
$>2.5 \mathrm{~kg}$ (Shepard) & 4 & 78 & 82 \\
Total & 8 & 78 & 86 \\
\hline
\end{tabular}

According to the Shepard equation, sensitivity of detecting low birth weight babies was $50 \%$ while its specificity was $100 \%$.

Table 7. Sensitivity and specificity for detection of a newborn $<2.5 \mathrm{~kg}$ by Campbell equation

\begin{tabular}{|c|c|c|c|}
\hline & $<2.5 \mathrm{~kg}$ (actual) & $\geq 2.5 \mathrm{~kg}$ (actual) & Total \\
\hline$<2.5 \mathrm{~kg}$ (Campbell) & 2 & 2 & 4 \\
\hline$>2.5 \mathrm{~kg}$ (Campbell) & 6 & 76 & 82 \\
\hline Total & 8 & 78 & 86 \\
\hline
\end{tabular}

According to the Campbell equation, sensitivity of detecting low birth weight babies was $25.0 \%$ while its specificity was $97.4 \%$.

Table 8. Sensitivity and specificity for detection of a newborn $<2.5 \mathrm{~kg}$ by Campbell equation

\begin{tabular}{lccc}
\hline & $<2.5 \mathrm{~kg}$ (actual) & $\geq 2.5 \mathrm{~kg}$ (actual) & Total \\
\hline$<2.5 \mathrm{~kg}$ (Hadlock I) & 5 & 5 & 10 \\
$>2.5 \mathrm{~kg}$ (Hadlock I) & 3 & 73 & 76 \\
Total & 8 & 78 & 86 \\
\hline
\end{tabular}

According to the Hadlock I equation, sensitivity of detecting low birth weight babies was $62.5 \%$ while its specificity was $93.6 \%$.

Table 9. Sensitivity and specificity for detection of a newborn $<2.5 \mathrm{~kg}$ by Hadlock II equation

\begin{tabular}{lccc}
\hline & $<2.5 \mathrm{~kg}$ (actual) & $\geq 2.5 \mathrm{~kg}$ (actual) & Total \\
\hline$<2.5 \mathrm{~kg}$ (Hadlock II) & 5 & 4 & 09 \\
$>2.5 \mathrm{~kg}$ (Hadlock II) & 3 & 74 & 77 \\
Total & 8 & 78 & 86 \\
\hline
\end{tabular}

According to the Hadlock II equation, sensitivity of detecting low birth weight babies was $62.5 \%$ while its specificity was $94.9 \%$. 
Table 10. Sensitivity and specificity for detection of a newborn $<2.5 \mathrm{~kg}$ by Hadlock III equation

\begin{tabular}{lccc}
\hline & $<2.5 \mathrm{~kg}$ (actual) & $\mathbf{2 . 5} \mathbf{k g}$ (actual) & Total \\
\hline$<2.5 \mathrm{~kg}$ (Hadlock III) & 5 & 1 & 06 \\
$>2.5 \mathrm{~kg}$ (Hadlock III) & 3 & 77 & 80 \\
Total & 8 & 78 & 86 \\
\hline
\end{tabular}

According to the Hadlock III equation, sensitivity of detecting low birth weight babies was $62.5 \%$ while its specificity was $98.7 \%$.

Table 11. Sensitivity and specificity for detection of a newborn $<2.5 \mathrm{~kg}$ by Hadlock IV equation

\begin{tabular}{lccc}
\hline & $<2.5 \mathrm{~kg}$ (actual) & $\geq 2.5 \mathrm{~kg}$ (actual) & Total \\
\hline$<2.5 \mathrm{~kg}$ (Hadlock IV) & 6 & 4 & 10 \\
$>2.5 \mathrm{~kg}$ (Hadlock IV) & 2 & 74 & 76 \\
Total & 8 & 78 & 86 \\
\hline
\end{tabular}

According to the Hadlock IV equation, sensitivity of detecting low birth weight babies was $75.0 \%$ while its specificity was $94.9 \%$.

Sensitivity and specificity for detection of a newborn $>3.5 \mathrm{~kg}$.

Table 12. Sensitivity and specificity for detection of a newborn $>3.5 \mathrm{~kg}$ by Shepard equation

\begin{tabular}{lccc}
\hline & $<3.5 \mathrm{~kg}$ (actual) & $\leq 3.5 \mathrm{~kg}$ (actual) & Total \\
\hline$<3.5 \mathrm{~kg}$ (Shepard) & 9 & 27 & 36 \\
$\leq 3.5 \mathrm{~kg}$ (Shepard) & 1 & 49 & 50 \\
Total & 10 & 76 & 86 \\
\hline
\end{tabular}

According to the Shepard equation, sensitivity of detecting large birth weight babies was $90.0 \%$ while its specificity was $64.5 \%$.

Table 13. Sensitivity and specificity for detection of a newborn $>3.5 \mathrm{~kg}$ by Campbell equation

\begin{tabular}{lccc}
\hline & $<3.5 \mathrm{~kg}$ (actual) & $\mathbf{3} .5 \mathrm{~kg}$ (actual) & Total \\
\hline$<3.5 \mathrm{~kg}$ (Campbel) & 7 & 10 & 17 \\
$\leq 3.5 \mathrm{~kg}$ (Campbel) & 3 & 66 & 69 \\
Total & 10 & 76 & 86 \\
\hline
\end{tabular}

According to the Campbell equation, sensitivity of detecting large birth weight babies was $70.0 \%$ while its specificity was $86.8 \%$. 
Table 14. Sensitivity and specificity for detection of a newborn $>3.5 \mathrm{~kg}$ by Hadlock I equation

\begin{tabular}{lccc}
\hline & $<3.5 \mathrm{~kg}$ (actual) & $\leq 3.5 \mathrm{~kg}$ (actual) & Total \\
\hline$<3.5 \mathrm{~kg}$ (Hadlock I) & 8 & 08 & 16 \\
$\leq 3.5 \mathrm{~kg}$ (Hadlock I) & 2 & 68 & 70 \\
Total & 10 & 76 & 86 \\
\hline
\end{tabular}

According to the Hadlock I equation, sensitivity of detecting large birth weight babies was $80.0 \%$ while its specificity was $89.5 \%$.

Table 15. Sensitivity and specificity for detection of a newborn $>3.5 \mathrm{~kg}$ by Hadlock II equation

\begin{tabular}{lccc}
\hline & $<3.5 \mathrm{~kg}$ (actual) & $\leq 3.5 \mathrm{~kg}$ (actual) & Total \\
\hline$<3.5 \mathrm{~kg}$ (Hadlock II) & 7 & 09 & 16 \\
$\leq 3.5 \mathrm{~kg}$ (Hadlock II) & 3 & 67 & 70 \\
Total & 10 & 76 & 86 \\
\hline
\end{tabular}

According to the Hadlock II equation, sensitivity of detecting large birth weight babies was $70.0 \%$ while its specificity was $88.2 \%$.

Table 16. Sensitivity and specificity for detection of a newborn $>3.5 \mathrm{~kg}$ by Hadlock III equation

\begin{tabular}{lccc}
\hline & $<3.5 \mathrm{~kg}$ (actual) & $\leq 3.5 \mathrm{~kg}$ (actual) & Total \\
\hline$<3.5 \mathrm{~kg}$ (Hadlock III) & 7 & 07 & 14 \\
$\leq 3.5 \mathrm{~kg}$ (Hadlock III) & 3 & 69 & 72 \\
Total & 10 & 76 & 86 \\
\hline
\end{tabular}

According to the Hadlock III equation, sensitivity of detecting large birth weight babies was $70.0 \%$ while its specificity was $90.8 \%$.

Table 17. Sensitivity and specificity for detection of a newborn $>3.5 \mathrm{~kg}$ by Hadlock IV equation

\begin{tabular}{lccc}
\hline & $<3.5 \mathrm{~kg}$ (actual) & $\leq 3.5 \mathrm{~kg}$ (actual) & Total \\
\hline$<3.5 \mathrm{~kg}$ (Hadlock IV) & 4 & 02 & 06 \\
$\leq 3.5 \mathrm{~kg}$ (Hadlock IV) & 6 & 74 & 80 \\
Total & 10 & 76 & 86 \\
\hline
\end{tabular}

According to the Hadlock IV equation, sensitivity of detecting large birth weight babies was $40.0 \%$ while its specificity was $97.4 \%$. 


\section{Discussion}

Ultrasound scan is a most popular investigation in current obstetric practice in our setup at various purposes. It ranges from very early pregnancy to see the intrauterine gestation, to the term to obtain estimated fetal weight, to see presentation in uncertain situations and assessment of fetal wellbeing.

Serial measurements of estimated fetal weight are superior to single measurement of EFW in prediction of fetal growth restriction ${ }^{37}$. Determination of fetal weight by USS is depend on the formulae which are designed to predict fetal weight. These each formulae use one or few fetal biometric measurements for calculation of fetal weight.

We considered the equations of Shepard, Campbell, Hadlock I, II, III and IV because these are the commonly used formulae to estimate fetal weight at our set up and were incorporated in the study.

In the current study a significant high degree of positive correlation between the ABW and the EFW was seen. The formula of Hadlock IV had the highest positive correlation with $\mathrm{ABW}$ among six formulae $(\mathrm{r}=0.836)$. The formula of Campbell had the lowest positive correlation with $\mathrm{ABW}(\mathrm{r}=0.787)$. Most of the previous studies had shown that there was a positive correlation between the ABW and EFW by different formulae. The present study also showed similar results. As example, the study by Nahum $G G^{3}$ had shown that the Hadlock and Shepard formulae had a positive correlation with $\mathrm{ABW}$ in which Hadlock formula had a better correlation with $\mathrm{ABW}$ than Shepard.

A study done in Singapore showed that Even though the Hadlock formula was originally derived from an American population, it was equally useful in south-east Asian population. Sri Lankans are being the South Asians this study also shows the similar findings ${ }^{28}$.

When sensitivity for detection of fetuses less than $2.5 \mathrm{~kg}$ out of whole population for each formula was compared the Hadlock IV has the highest sensitivity which is $75 \%$ while Campbell formula has the lowest sensitivity. All the formulae have the high specificity which ranges from $93.6 \%$ to $100 \%$. According to the results the Hadlock IV formula is the best formula to predict babies less than $2.5 \mathrm{~kg}$.

However in a study done by Siemer $J$ and his team in Germany showed that Hadlock II and III formulae best to predict EFW in fetuses less than 2.5 $\mathrm{kg} 38$ by evaluating the best formula for small birth weight category ${ }^{26}$.
When compared in the birth weight category of more than $3.5 \mathrm{~kg}$ the Shepard has the highest sensitivity which is $90 \%$ and the Hadlock IV has the lowest sensitivity for detection of a large baby. The specificity is highest $(97.4 \%)$ in Hadlock IV while the Shepard has the lowest (64\%) specificity. Even though the Hadlock IV is the best formula identified in our study to predict babies less than $2.5 \mathrm{~kg}$ out of whole population, it is not best for prediction of a baby larger than $3.5 \mathrm{~kg}$ (Hadlock IV sensitivity $40 \%$ ) compared to Hadlock I (sensitivity $80 \%$ and specificity $89.5 \%$ ) which is the best formula to predict a baby more than $3.5 \mathrm{~kg}$.

ROC curve for each formula shows Hadlock IV is the best formula for fetal weight prediction out of 6 formulae in this study because Hadlock IV formula shows the maximum area under the curve. A Campbell formula was the least accurate out of the 6 formulae. Therefore the Hadlock IV formula is the best formula for fetal weight estimation in our study.

The Hadlock IV formula uses 4 biometric measurements (BPD, HC, AC, and FL) for estimation of fetal weight while Campbell uses only $A C$ for its calculation. Number of fetal biometric measurements appears to the accuracy.

However. when other sonographic fetal measurements, for example humeral soft tissue thickness, ratio of subcutaneous tissue to $\mathrm{FL}$ and cheek-to-cheek diameter are used to estimate fetal weight, these nonstandard measurements do not significantly improve the ability of obstetric sonography to help predict birth weight ${ }^{22}$. while in another study, three-dimensional (3D) volumetric measurements of the fetal thigh, upper arm and abdomen were performed together with conventional twodimensional (2D) biometry and concluded that 3D sonography allows superior fetal weight estimation by including soft tissue volume ${ }^{23}$.

This descriptive cross-sectional study demonstrated that fetal weight could be estimated accurately and reliably by USS examination, especially at term, using any of the six formulae while the Hadlock IV formula remains as the most accurate formula for estimation of fetal weight.

One of the main limitations of this Study was that it carried out in an obstetric unit in a tertiary care centre which may not represent a typical Sri Lankan population. A multicentre study involving several districts in Sri Lanka may represent a more homogenous Sri Lankan population. 


\section{Conclusion}

It could be concluded that while all formulae have adequate accuracy for estimating fetal weight in the population tested, Hadlock IV has the best accuracy.

\section{References}

1. Boyd ME, Usher RH and McLean FH. Fetal macrosomia: prediction, risks, proposed management. Obstetric Gynecology 1983; 61(6): 715-22.

2. A.Japarath P, Wiboolphan T. Comparison of the Accuracy of Fetal Weight Estimation Using Clinical and Sonographic Methods. J Med Assoc Thai 2004; 87(Suppl): S1-7.

3. Gerard G, Nahum, Harold Stanislaw. Ultrasonographic prediction of term birth weight: How accurate is it? Am J Obstetric Gynecology 2003; 566-73.

4. Bernstein IM, Horbar JD, Badger GJ, Ohlsson, Golan A. Morbidity and mortality among very low birth weight neonates with intrauterine growth restriction. Am J Obstetric Gynecology 2000; 182: 198-206.

5. D.Keith Edmonds, Dewhurst S. Textbook of Obstetrics and Gynecology 2007; 161-2

6. David K, James, Philip J.Steer, Carl P. Weiner, Bernard Gonik. High risk pregnancy management options (2nd edn) 1999; 1133-4.

7. Nesbitt TS, Gilbert WM, Herrchen B. Shoulder dystocia and associated risk factors with macrosomic infants born in California. Am J Obstetric Gynaecology 1998; 179(2): $476-80$

8. Sultan $\mathrm{AH}$, Stanton SL. Preserving the pelvic floor and perineum during child birth/ Elective cesarean section. $\mathrm{Br}$ J Obstetric Gynaecol 1996; 103: 731-4.

9. De Leeuw JW, Struijk PC, Vierhout ME, Wallenburg HCS Risk factors for third degree perineal ruptures during delivery. British Journal of Obstetrics and Gynecology 2001; 108: 383-7.

10. Campbell S and Wilkin D. Ultrasonic measurement of fetal abdomen Circumference in the estimation of fetal weight: Br J Obstet Gynaecol 1975; 82: 689-97.

11. Asim Kurjak, Frank A Chervenak. Donald School Textbook of Ultrasound in Obstetrics and Gynecology (1st edn) 2004; 212-9.

12. Benacerraf BR, Gelman R, Frigoletto FD. Sonographically estimated fetal weights: accuracy and limitation. Am J Obstet Gynecol 1988; 159(5): 1118-23.

13. Chauhan SP, Cowan BD, Magann EF, et al. Intrapartum detection of a macrosomic fetus. clinical versus 8 sonographic models. N Z J Obstet Gynaecol 1995; 35(3): 266-70.

14. Hadlock F P, Harris R B, Sharman RS, Deter R L and Park $S K$. Estimation of fetal weight with the use of head, body and femur measurements, a prospective study. Am J Obstet Gynecol 1985; 151: 333-7.

15. Warsof, SL, Gohari, P, Berkowitz, RL, Hobbins, JC. The estimation of fetal weight by computer-assisted analysis. Am J Obstet Gynecol 1977; 128: 881.
16. Shepard MJ, Richards VA, Berkowitz RL, et al. An evaluation of two equations for predicting fetal weight by ultrasound. Am J Obstet Gynecol 1982; 142: 47.

17. Hadlock, FP, Harrist, RB, Fearneyhough, TC, et al. Use of femur length/abdominal circumference ratio in detecting the macrosomic fetus. Radiology 1985; 154: 503.

18. Hadlock FP, Harrist RB, Sharman RS, et al. Estimation of fetal weight with the use of head, body, and femur measurements, a prospective study. Am J Obstet Gynecol 1985; 151: 333.

19. 'Sherman DJ, Arieli S, Tovbin J, et al: A comparison of clinical and ultrasonic estimation of fetal weight. Obstetric Gynecology 1998; 91(2): 212-7.

20. Frank P. Hadlock, Ronald B. Harrist, Robert J. Carpenter Russel L. Deter and Seung K. Park. Sonographic estimation of fetal weight, The value of femur length in addition to head and abdomen measurements. Radiology 1984; 150(2): 535-7.

21. Hadlock FP, Harrist RB, Carpenter RJ, Deter RL, Park SK. Sonographic estimation of fetal weight. Radiology 1984; 150: $535-40$.

22. Dhiraj Man Shrestha, Sunil Pradan, BenuLohani, Jyoti Sharma. Sonographic estimation of fetal weight: evaluation of five formulas. Research bulletin, Research Division, Tribhuvan University. 2006; 24(1): 3-4.

23. Schild RL, Fimmers R, Hansmann M. Fetal weight estimation by three-dimensional ultrasound ultrasound. Obstetric Gynecol. 2000; 16(5): 445-52.

24. Platek DN, Divon MY, Anyaegbunam A, Merkatz IR. Intrapartumultrasonographic estimates of fetal weight by the house staff. Am J Obstetric Gynecology 1991; 165: 842-5.

25. Sarmandal P, Bailey SM, Grant JM. A comparison of three methods of assessing inter-observer variation applied to ultrasonic fetal measurement in the third trimester. $\mathrm{Br}$ I Obstetric Gynaecol 1989; 96(11): 1261-5.

26. Siemer J, Peter W, Zollver H, Hart N, Muller A, Maurer B, Goecke $T$ and Schild RL. How good is fetal weight estimation using volumetric methods? Ultraschall Med. 2008; 29(4): 377-82.

27. Donma MM, Donma O and Sonmez S. Prediction of birth weight by ultrasound in Turkish population; which formula should be used in Turkey to estimate fetal weight? Ultrasound Med Biol. 2005; 31(12): 1577-81.

28. Venkat A, Chinnaiya A, Gopal M and Mongelli JM Sonographic fetal weight estimation in a south-east Asian population. J Obstetric Gynaecol Res. 2001; 27(5): 275-9.

29. Zaretsky MV, Reichel TF, McIntire DD, Twickler DM Comparison of magnetic resonance imaging to ultrasound in the estimation of birth weight at term. Am J Obstetric Gynecol. 2003; 189(4): 1017-20.

30. Stratton J, Ní Scanaill S, Stuart B, Turner MJ. Which formula should be used in Ireland to estimate fetal weight? Ir Med J. 1996; 89(1): 30-1.

31. Carranza Lira S, Haro Gonzalez LM, Biruete Correa B. Comparison between clinical and ultrasonographic

Sri Lanka Journal of Obstetrics and Gynaecology 
measurements to estimate fetal weight during labor: a new clinical calculation formula.Gynecol Obstetric Mex. 2007; 75(10): 582-7.

32. Shepard M and Filly RA .A standardized plane for biparietal diameter measurement. J Ultrasound Med. 1982; 1: 145.

33. Kurtz $\mathrm{AB}$ and Needleman L. Ultrasound assessments of fetal age. In. Callen PW (ed). Ultrasonography in Obstetricsand Gynaecology 2nded Philadelphia: Saunders; 1988: p 55.

34. Abrams SI, Filly RA. Curvature of the fetal femur. A normal sonographic finding. Radiology. 1985; 156: 490.

35. Sabbagha RE, Minogue J, Tamura RK, et al: Estimation of birth weight by use of ultrasonographic formulas targeted to large, appropriate, and small-for-gestational-age fetuses. Am J Obstetric Gynecology 1989; 160(4): 854-60; discussion 860-2.

36. E Albert Reece, MD, et al. The safety of obstetric ultrasonography: Concern for the fetus. Obstetrics and Gynecology 1990; 76(1); 139-46.

37. Royal Collage of Obstetricians and Gynecologist. Guideline no 31. Nov 2002; 2-3.

38. Siemer J, Egger N, Hart N, Meurer B, Muller A, Dathe O, Goecke T, Schild RL. Fetal weight estimation by ultrasound: comparison of 11 different formulae and examiners with differing skill levels. Ultraschall Med. 2008; 29(2): 159-64. 